\title{
InGaAs Diodes for Terahertz Sensing-Effect of Molecular Beam Epitaxy Growth Conditions
}

\author{
Vilius Palenskis ${ }^{1}$, Linas Minkevičius ${ }^{2}$, Jonas Matukas ${ }^{1}$, Domas Jokubauskis ${ }^{2, *}$ (]), \\ Sandra Pralgauskaitè ${ }^{1}$, Dalius Seliuta ${ }^{2}$, Bronislovas Čechavičius ${ }^{2}{ }^{(0}$, Renata Butkutè ${ }^{2}$ (D) and \\ Gintaras Valušis ${ }^{2}$ \\ 1 Institute of Applied Electrodynamics and Telecommunications, Physics Faculty, Vilnius University, \\ Sauletekio ave. 3, 10257 Vilnius, Lithuania; vilius.palenskis@ff.vu.lt (V.P.); jonas.matukas@ff.vu.lt (J.M.); \\ sandra.pralgauskaite@ff.vu.lt (S.P.) \\ 2 Department of Optoelectronics, Center for Physical Sciences and Technology, Savanoriu ave. 231, \\ 02300 Vilnius, Lithuania; linas.minkevicius@ftmc.lt (L.M.); dalius.seliuta@ftmc.lt (D.S.); \\ bronislovas.cechavicius@ftmc.lt (B.Č.); renata.butkute@ftmc.lt (R.B.); gintaras.valusis@ftmc.lt (G.V.) \\ * Correspondence: domas.jokubauskis@ftmc.lt; Tel.: +370-5-2312418
}

Received: 3 October 2018; Accepted: 30 October 2018; Published: 3 November 2018

\begin{abstract}
InGaAs-based bow-tie diodes for the terahertz (THz) range are found to be well suited for development of compact $\mathrm{THz}$ imaging systems. To further optimize design for sensitive and broadband $\mathrm{THz}$ detection, one of the major challenges remains: to understand the noise origin, influence of growth conditions and role of defects for device operation. We present a detailed study of photoreflectance, low-frequency noise characteristics and $\mathrm{THz}$ sensitivity of InGaAs bow-tie diodes. The diodes are fabricated from InGaAs wafers grown by molecular beam epitaxy (MBE) on semi-insulating InP substrate under different technological conditions. Photoreflectance spectra indicated the presence of strong built-in electric fields reaching up to $49 \mathrm{kV} / \mathrm{cm}$. It was demonstrated that the spectral density of voltage fluctuations at room temperature was found to be proportional to $1 / f$, while at lower temperatures, 77-200 K, Lorentzian-type spectra dominate due to random telegraph signals caused by individual capture defects. Furthermore, varying bias voltage, we considered optimal conditions for device room temperature operation in the $\mathrm{THz}$ range with respect to signal-to-noise ratio. The $\mathrm{THz}$ detectors grown with beam equivalent pressure $\mathrm{In} / \mathrm{Ga}$ ratio equal to 2.04 exhibit the minimal level of the low-frequency noise, while InGaAs layers grown with beam equivalent pressure In/Ga ratio equal to 2.06 are found to be well suited for fabrication of room temperature bow-tie $\mathrm{THz}$ detectors enabling sensitivity of $13 \mathrm{~V} / \mathrm{W}$ and noise equivalent power (NEP) of $200 \mathrm{pW} / \sqrt{ } \mathrm{Hz}$ at $0.6 \mathrm{THz}$ due to strong built-in electric field effects.
\end{abstract}

Keywords: terahertz sensing; terahertz imaging; InGaAs diodes; molecular beam epitaxy; low-frequency noise; spectral density

\section{Introduction}

The InGaAs/InP material system is one of the key compounds for ultrafast optoelectronics applications [1]. It can also serve as a core element for other optoelectronics applications including infrared photosensors [2] and magnetic field sensors [3]. A particular importance of this material compound arises from the rapidly growing interests in its suitability for efficient $\mathrm{THz}$ emission excited by femtosecond laser pulses [4,5], THz photomixers [6-8], possible use in nanometric field effect transistors for electrically driven plasma-wave-related THz emission [9], and THz sensing [10].

The InGaAs/InP material system is employed in the development of planar bow-tie-shaped InGaAs diodes [11] which were found well-suited for direct [12], heterodyne [13] and spectroscopic 
imaging applications up to $2.52 \mathrm{THz}[14,15]$. The diode operates both due to nonuniform carrier heating and resistive mixing caused by applied external THz electric field inducing DC voltage over the terminals of the diode [16].

The diode exhibits low noise because its operation does not require application of the bias voltage. The choice of the InGaAs material is motivated due to its high electron mobility, $13,300 \mathrm{~cm}^{2} / \mathrm{V} \cdot \mathrm{s}$ at room temperature [11]; the detector sensitivity at room temperature is of about $6 \mathrm{~V} / \mathrm{W}$, whilst the relevant value in GaAs-based detectors is about $0.3 \mathrm{~V} / \mathrm{W}[17,18]$. The noise-equivalent power (NEP) of InGaAs diodes in direct and heterodyne modes is estimated to be about $4 \mathrm{nW} / \sqrt{ } \mathrm{Hz}$ and $0.23 \mathrm{pW} / \mathrm{Hz}$, respectively, for a local-oscillator power of $11 \mu \mathrm{W}$ [13].

Despite the fact that InGaAs bow-tie diode displays the advantages of broadband room temperature operation, rather uncomplicated fabrication process and good reliability, its NEP values need to be improved in comparison, for instance, to those of field effect transistors fabricated using CMOS technology (gate length is $150 \mathrm{~nm}$ ), where NEP amounts to $43 \mathrm{pW} / \sqrt{ } \mathrm{Hz}$ [19]. Therefore, to improve design of InGaAs-based bow-tie $\mathrm{THz}$ detectors, one needs to get deeper insight into origin of defects or recombination centers that may have impact on InGaAs layer and InGaAs/InAs/InP material interface properties.

Investigation of noise characteristics is well known as a highly sensitive method to reveal physical processes in various structures and devices as well as to enable the reliability prediction [20-22]. On the other hand, the noise level of a detector is the restricting factor of the imaging system sensitivity [23]. Preliminary investigation has shown that the spectral density of current fluctuations in bow-tie diodes changes with frequency approximately as $1 / f$ and allows us to predict that the origin of noise is a superposition of the capture and emission of charge carriers in defects of the structure [24].

In this article, we discuss effects of different technological conditions for the InGaAs devices fabricated from InGaAs layers grown by molecular beam epitaxy (MBE) on semi-insulating InP substrate. It was shown that structures exhibit presence of strong built-in electric fields reaching up to $49 \mathrm{kV} / \mathrm{cm}$, which were derived from the photoreflectance spectra. It was demonstrated that the spectral density of voltage fluctuations at room temperature is found to be proportional to $1 / f$, while at lower temperatures, 77-200 K, Lorentzian-type spectra dominate due to random telegraph signals caused by individual capture defects. The presented results demonstrate how InGaAs layers grown at different beam equivalent pressure (BEP) In/Ga ratios affect the low-frequency noise level and the sensitivity of the $\mathrm{THz}$ detectors. We underline that $\mathrm{THz}$ detectors grown with $\mathrm{BEP} \mathrm{In} / \mathrm{Ga}$ ratio equal to 2.06 are found to be most sensitive at room temperature.

\section{Grown Structures and Experimental Techniques}

The InGaAs layers for detectors were grown using the SVT-A MBE reactor on semi-insulating InP:Fe substrates oriented in the (100) crystallographic plane. Before the growth procedure, the surface of InP:Fe substrate was cleaned from native oxide by annealing at temperature of $500{ }^{\circ} \mathrm{C}$ for $10 \mathrm{~min}$. In order to prevent the loss of phosphorus on the surface of the substrate, the deoxidation was performed in flux at a pressure of about $5 \times 10^{-6}$ Torr in-situ observing the reflection high-energy electron diffraction (RHEED) pattern. After the native oxide removal, 1-2 monolayer (ML)-thick InAs was deposited. The thickness of the InAs layer was designed in such a way that it forms a structurally strained interlayer between the substrate and InGaAs. Then, the InGaAs layer was grown in a temperature range from $500^{\circ} \mathrm{C}$ to $515^{\circ} \mathrm{C}$ varying growth rate from $300 \mathrm{~nm} / \mathrm{h}$ to $600 \mathrm{~nm} / \mathrm{h}$. Growth rate was determined from RHEED intensity oscillations recorded for the specular beam. To optimize the growth conditions, the In/Ga BEP ratio varying from 2.04 to 2.08 was investigated.

The patterning of a 1.18- $\mu \mathrm{m}$-height mesa structure was carried out by optical lithography and wet etching [13]. The electrical contacts for detectors were deposited by thermal evaporation of 20-nm-thick Ti and 180-nm-thick Au. Contact layers after deposition were ex-situ annealed at $400{ }^{\circ} \mathrm{C}$ temperature for $10 \mathrm{~s}$ in nitrogen ambience using a rapid thermal annealing (RTA) oven. 
The crystalline structure of In and Ga content in different InGaAs samples has been investigated by measuring high-resolution X-ray diffraction (HRXRD) $\omega-2 \theta$ scans of the (400) reflex using $\mathrm{CuK}_{\alpha 1}$ radiation. The results of XRD rocking curve measurements are presented in Figure 1. From these data, the lattice constant has been evaluated. The lattice constant varied from $5.8639 \AA$ to $5.8687 \AA$ for InGaAs layers grown using In/Ga ratios from 2.04 to 2.08, respectively, and then the In and Ga content was obtained. It was found that for InGaAs layers well matched to the InP:Fe substrate growth, the BEP ratio of In/Ga of about 2.08 is optimum. The growth mechanism, completion of atomic layers and the surface roughness have been investigated by atomic force microscopy (AFM). The surface images of InGaAs epitaxial layers are shown in Figure 2. AFM revealed that surface roughness of investigated InGaAs layers varied from $0.166 \mathrm{~nm}$ (B204) to $0.322 \mathrm{~nm}$ (B203). It was demonstrated that lattice matched to the InP substrate epitaxial InGaAs layer exhibits much smoother surface due to the layer-by-layer growth mode.

The photoluminescence (PL) measurements were carried out using the DPSS laser $(532 \mathrm{~nm})$ for an excitation with the intensity reaching $\sim 600 \mathrm{~W} / \mathrm{cm}^{2}$ and the $0.4-\mathrm{m}$ monochromator. The PL was detected using a liquid nitrogen-cooled InGaAs point photodetector, whose signal was recorded using a lock-in amplifier when the laser radiation intensity had been modulated by a mechanical chopper set to $190 \mathrm{~Hz}$ modulation frequency.

The photoreflectance (PR) measurements were performed using a DPSS laser (532 nm) with modulation pump source chopped at $190 \mathrm{~Hz}$. The pump beam intensity was kept below $5 \mathrm{~mW} \mathrm{~cm} \mathrm{c}^{-2}$.

Noise characteristics at forward and backward bias were measured within the frequency range from $10 \mathrm{~Hz}$ to $20 \mathrm{kHz}$ varying lattice temperature from $77 \mathrm{~K}$ to $300 \mathrm{~K}$. The experimental setup [24] is described in detail in Supplementary Materials.

Terahertz sensitivity was evaluated measuring responsivity of the InGaAs bow-tie detectors at frequency of $0.3 \mathrm{THz}$ and $0.6 \mathrm{THz}$ employing an electronic multiplier chain (Virginia Diodes, Inc. Charlottesville, VA, USA) as THz radiation source.

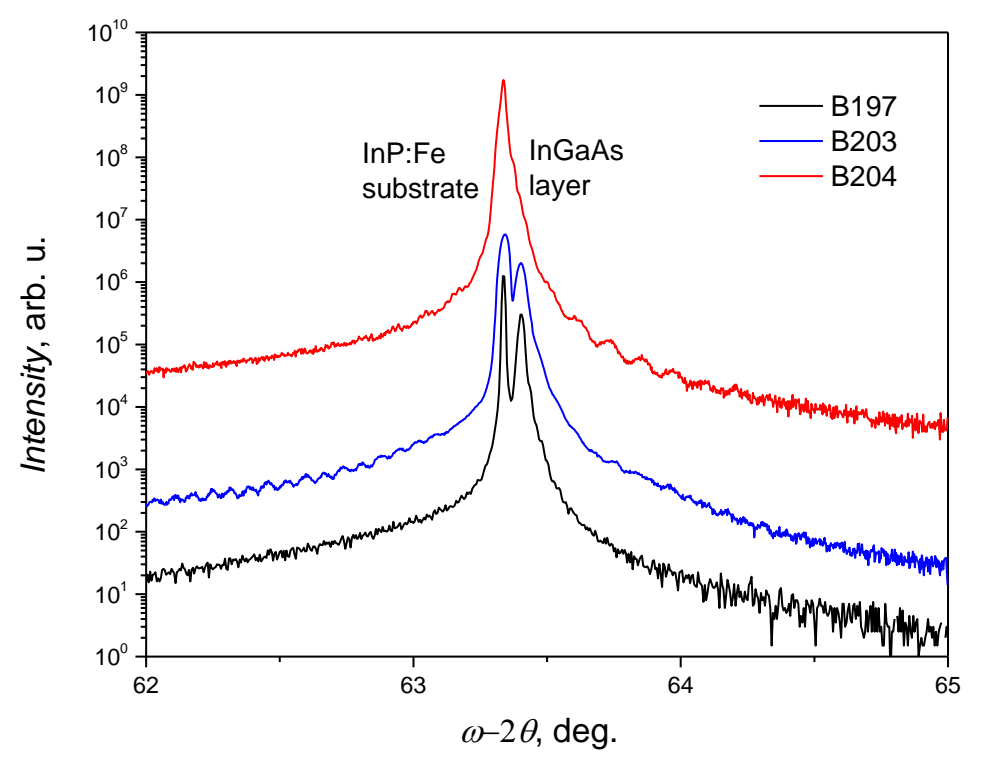

Figure 1. The rocking curves of (400) reflex of X-ray diffraction measured for detectors grown with different BEP In/Ga ratios: 2.04 (sample B197), 2.06 (sample B203), and 2.08 (sample B204).

The AFM images (Figure 2) show the surface morphology obtained on GaInAs epitaxial layers, grown using different BEP In/Ga ratios (2.04-B197, 2.06-B203, and 2.08-B204). Scanned surface area is $1.5 \times 0.7 \mu \mathrm{m}^{2}$. The color scale of $4 \mathrm{~nm}$ resolution demonstrates surface roughness measured from peak ( $\mathrm{min}$ ) to peak (max). The roughness values measured on the surfaces of B197, B203 and B204 samples are presented in Table 1. The surface morphology of all investigated samples is very smooth and the roughness does not exceed $1 \mathrm{ML}$. Also, it is clearly seen from the obtained images for B197 and 
B203 samples (they are grown at the same temperature of about $500{ }^{\circ} \mathrm{C}$ but using different In/Ga ratios) that the atomic traces on the B203 image are wider and exhibit higher quality than B197. On the other hand, the contrast of colors on the B204 sample image is the lowest and shows the highest crystallinity.
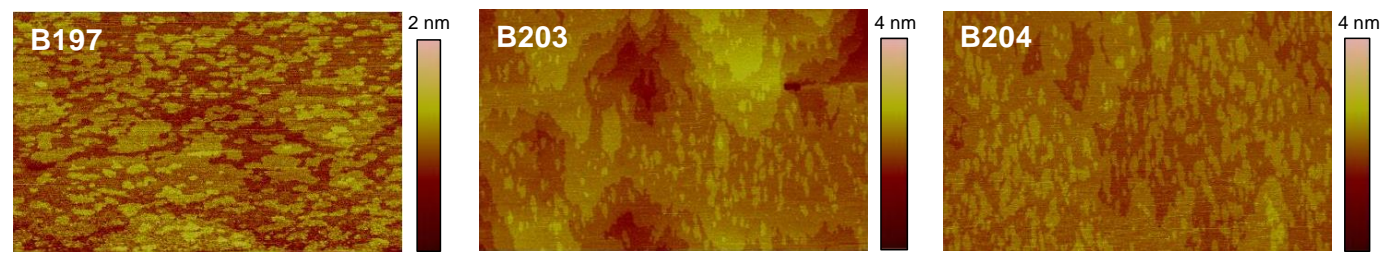

Figure 2. The surface morphology images of InGaAs epitaxial layers, grown using different BEP In/Ga ratios (2.04-B197, 2.06-B203, and 2.08-B204), obtained by atomic force microscopy. Scanned area is $1.5 \times 0.7 \mathrm{~m}^{2}$.

Table 1. Technological conditions and parameters of characterization of investigated bow-tie detectors: $\mathrm{BEP}$ - beam equivalent pressure; $\Delta 2 \theta$-misalignment between the (400) reflexes of InP substrate and InGaAs epilayer; content of In in percent; $d$ —thickness of InGaAs, nm; rms—surface roughness, nm; $R$-resistance, $\Omega$; E-emission energy, $\mathrm{eV}$.

\begin{tabular}{cccc}
\hline Samples & B197 & B203 & B204 \\
\hline BEP ratio In/Ga & 2.04 & 2.06 & 2.08 \\
$\Delta 2 \theta$, deg. & -0.07 & -0.064 & 0 \\
In, \% & 47.0 & 52.5 & 53.2 \\
InGaAs layer thickness, $d, \mathrm{~nm}$ & 540 & 540 & 540 \\
rms, nm & 0.167 & 0.322 & 0.166 \\
$R, \Omega$ & $470-500$ & $850-900$ & $770-780$ \\
$E, \mathrm{eV}$ & 0.739 & 0.736 & 0.735 \\
\hline
\end{tabular}

Figure 3 presents PL spectra measured at room temperature on three 540-nm-thick InGaAs layers grown in varying BEP ratios of In and Ga elements. It is seen that PL peak position is slightly shifted to the lower energies with increase of BEP ratio (In/Ga) from 2.04 to 2.08 (this ratio corresponds to the GaInAs composition lattice-matched to InP substrate). Although the full width at half maximum (FWHM) is less than $50 \mathrm{meV}$ for all three layers, the B204 sample grown at substrate temperature of about $510{ }^{\circ} \mathrm{C}$ demonstrates the higher crystalline quality and the narrowest FWHM value $(\sim 40 \mathrm{meV})$.

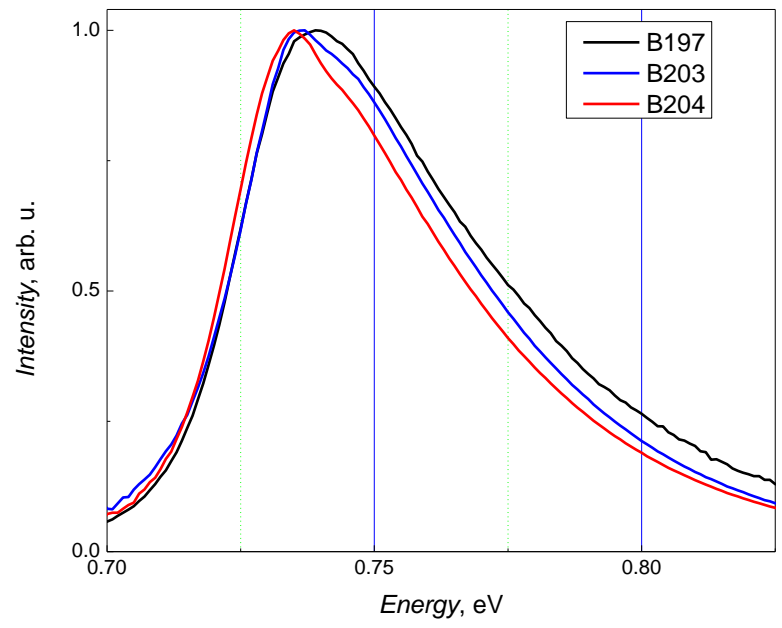

Figure 3. Room temperature photoluminescence spectra of three GaInAs samples: sample B197 (black line), B203 (blue line) and B204 (red line) grown using different BEP In/Ga ratios ranging from 2.04, 2.06 and 2.08, respectively, for B197, B203 and B204 at two substrate temperatures of about $500{ }^{\circ} \mathrm{C}$ (sample B197 and B203) and $510{ }^{\circ} \mathrm{C}$ (sample B204). 
Room temperature PR spectra for the epitaxial InGaAs layers are shown in Figure 4. The spectra are dominated by characteristic oscillations. These PR features are associated with Franz-Keldysh oscillations (FKOs) indicating the existence of the internal electric field in the samples. By analysing FKOs above the band edge, it is possible to estimate the strength of the electric field. In the analysis of the electric field strength, the extremes of the FKOs are given by [25]

$$
m \pi=\frac{4}{3}\left(\frac{E_{m}-E_{g}}{\hbar \theta}\right)^{3 / 2}+\varphi
$$

where $m$ is the index of the $m$-th extremum, $E_{m}$ is the photon energy of the $m$-th extremum, $E_{g}$ is the band gap of InGaAs, $\varphi$ is a phase factor. Electro-optic energy $\hbar \theta$ is given by $(\hbar \theta)^{3}=e^{2} F^{2} \hbar^{2} / 2 \mu$, and depends on electric field $F$, and charge carrier reduced mass $\mu$. Figure $4 \mathrm{~b}$ depicts the quantity $(4 / 3 \pi)\left(E_{m}-E_{g}\right)^{3 / 2}$ plotted versus Franz-Keldysh oscillations index $m$. As it is seen, the function is linear (solid lines show linear fit to Equation (1)), and from the slope it allows one to evaluate the electro-optic energy, and, hence, to determine the built-in electric field strength in the structure [26]. Evaluation indicates that the strongest electric field—reaching $49 \mathrm{kV} / \mathrm{cm}$-contains the structure B203. Technological characteristics of the investigated samples are summarized in Table 1.
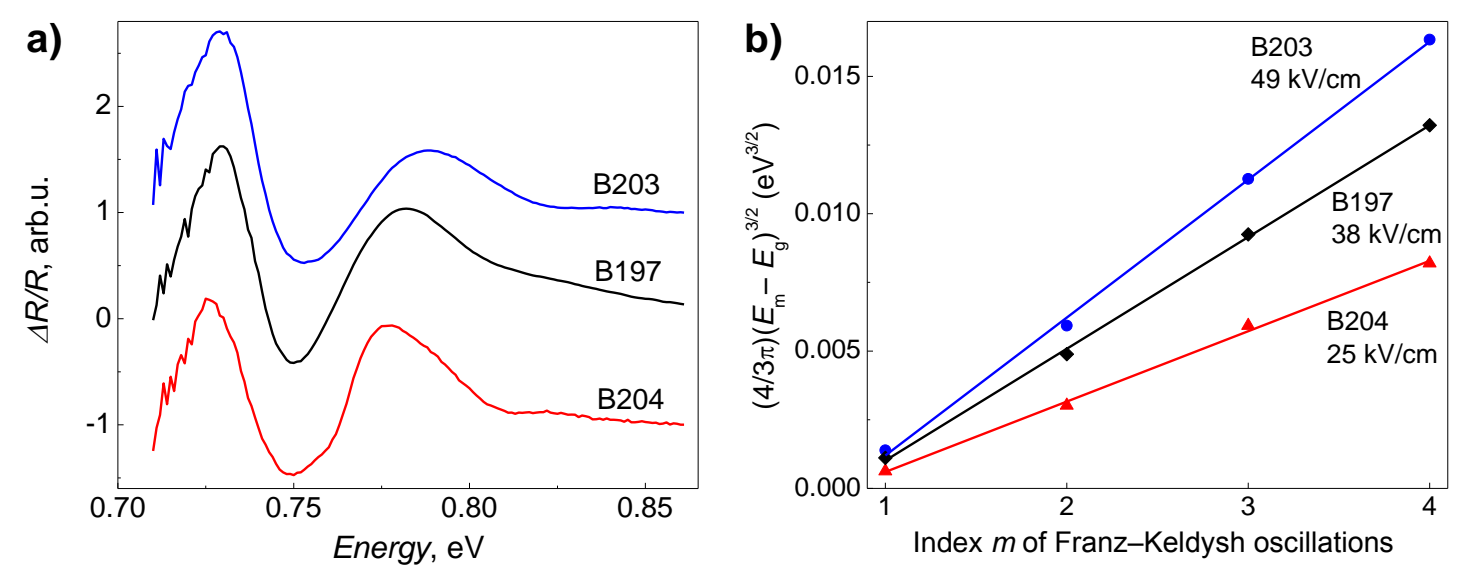

Figure 4. Photoreflectance spectra of InGaAs layers (a), each spectrum shifted vertically by 1 for clarity; and plots of the quantity $(4 / 3 \pi)\left(E_{m}-E_{g}\right)^{3 / 2}$ versus index $m$ of Franz-Keldysh oscillations for epitaxial layers (b).

\section{Low-Frequency Noise Measurement Results and Discussion}

\subsection{Investigation of the Resistivity of the Detectors}

Typical current-voltage characteristics of the investigated bow-tie $\mathrm{THz}$ detectors at room temperature are represented in Figure 5, and the dependence of resistance on temperature at low biases is shown in Figure 6. As it is seen from Figure 5, detector's B197 resistance is smaller than the other detectors at room temperature. Besides, the asymmetry of $I-U$ characteristics for diode B203 and B204 is higher than those for B197 (Figure 5b). It is worth noting that at temperatures $T>200 \mathrm{~K}$, the resistances slowly decrease with increase in temperature (Figure 6a), while at $T<200 \mathrm{~K}$ the resistances increase steeper with the decrease in temperature, especially characteristic for the detector B197. Such resistance changes with temperature can be described in terms of the activation energy (Figure $6 \mathrm{~b}$ ). The decrease of the activation energy $\Delta E$ with temperature observed for the sample B204 can be explained by the electron hopping mechanism in the impurity band in the energy gap of the semiconductor. 

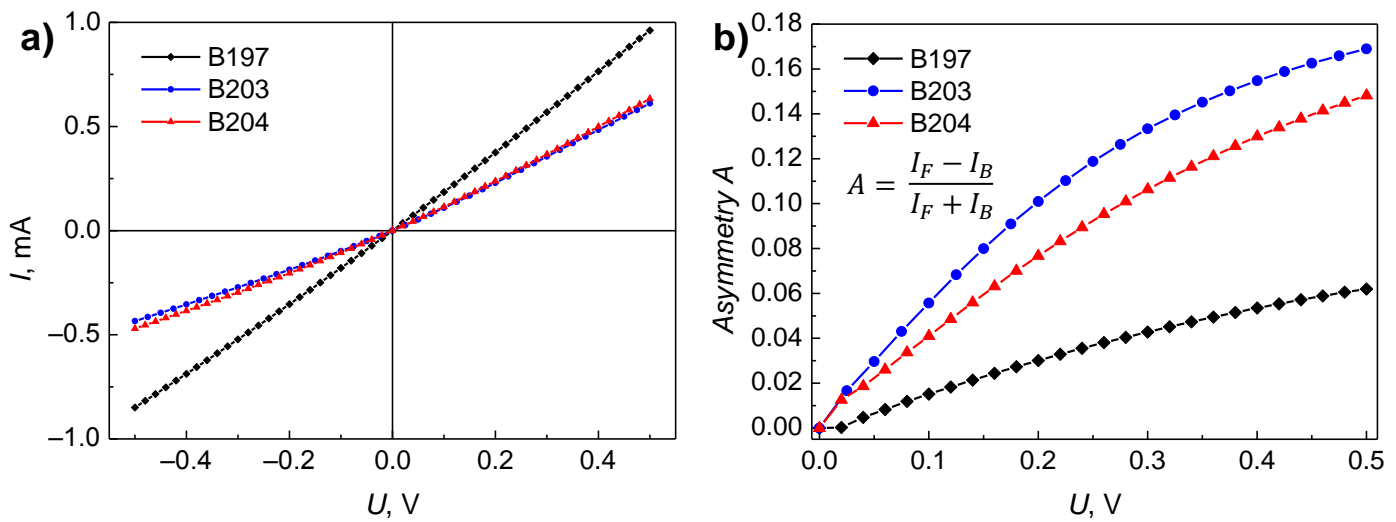

Figure 5. The current-voltage characteristics of InGaAs bow-tie detectors at room temperature (298 K) (a) and evaluated asymmetry (b), where $I_{F}$ and $I_{B}$ are forward and backward current values, respectively, at selected voltages.
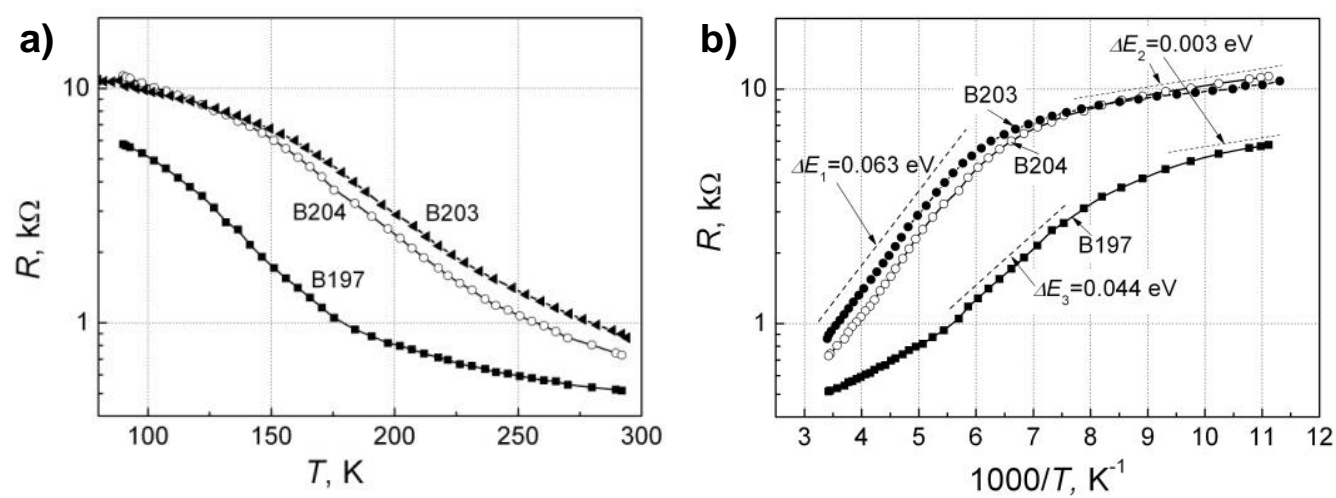

Figure 6. Temperature dependences of the resistance of the investigated bow-tie detectors B197, B203 and B204 in the linear part of $I-V$ characteristics (a). The activated temperature dependences of the resistances of bow-tie detectors as a function of $1000 / T$ (b).

According to the Mott model, the charge carriers are transported via thermally activated tunneling of electrons between the localized states which are randomly distributed in energy and position [27,28]. Then, the electrical conductivity can be described as

$$
\sigma \sim \exp \left(-\left(\frac{T_{0}}{T}\right)^{-\frac{1}{4}}\right),
$$

where

$$
T_{0}=\frac{\lambda \alpha^{3}}{\left(N\left(E_{F}\right) k\right)},
$$

$\lambda$ labels the dimensionless constant, $\alpha^{-1}$ is the localization length of the wave function for localized states, $N\left(E_{\mathrm{F}}\right)$ denotes the localized state density at the Fermi level, and $k$ is the Boltzmann's constant. $T_{0}$ is the quantity with temperature units, which determines the rate of conductivity change with temperature.

\subsection{Investigation of the Low-Frequency Noise of the Detectors}

Typical low-frequency noise spectra of the investigated InGaAs bow-tie detector B204 at different forward bias at room temperature $(298 \mathrm{~K}$ ) are presented in Figure 7 (the noise spectra for other samples as well as backward current direction at room temperature are almost the same as for the forward current direction, and therefore are not given here). The $1 / f$-type-voltage noise spectra show that 
the observed fluctuations are caused by the superposition of the charge carrier capture and emission processes in defects in the InGaAs layer and its interfaces [29-31].

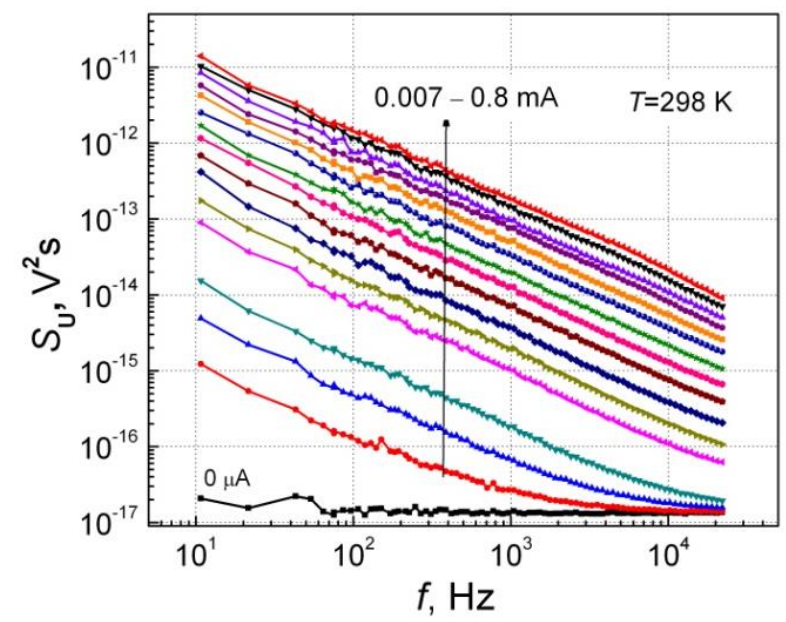

Figure 7. Voltage fluctuation spectra at different forward currents at room temperature for sample B204. The dependences for other samples are very similar.

A detailed description of the generation of noise with spectrum $1 / f$-type is presented in $[29,30]$. The low-frequency noise level caused by the charge carrier capture in localized states of defects in homogeneous semiconductors can be described as [31]

$$
S_{U}(f) / \mathrm{U}^{2}=S_{R}(f) / R^{2}=\left[0.16 K(1+\beta)^{2}\right] /\left(N^{2} f\right),
$$

where $S_{R}(f)$ is power spectral density of the resistance fluctuation $\Delta R(t) ; K \geq 1$ is the average number of relaxators (localized capture centers) in the sample with arbitrarily distributed relaxation times in every double octave of relaxation times; $N$ is the total number of free carriers in the sample; and $\beta$ is the parameter that describes the contribution of the mobility of the charge carriers' fluctuation to the total resistance fluctuation due to the free charge carrier capture process.

The dependences of the spectral density of voltage fluctuations on forward and backward bias current are shown in Figure 8. From the comparison of Figures 5 and 8, it is seen that in the linear current-voltage characteristics range $(U<0.2 \mathrm{~V})$, the spectral density of voltage fluctuations can be expressed by detector's resistance, $R$, and fluctuation spectral density $S_{R}(f)$ [18]:

$$
S_{U}(f)=U^{2} \frac{S_{R}(f)}{R^{2}}=I^{2} S_{R}(f) .
$$
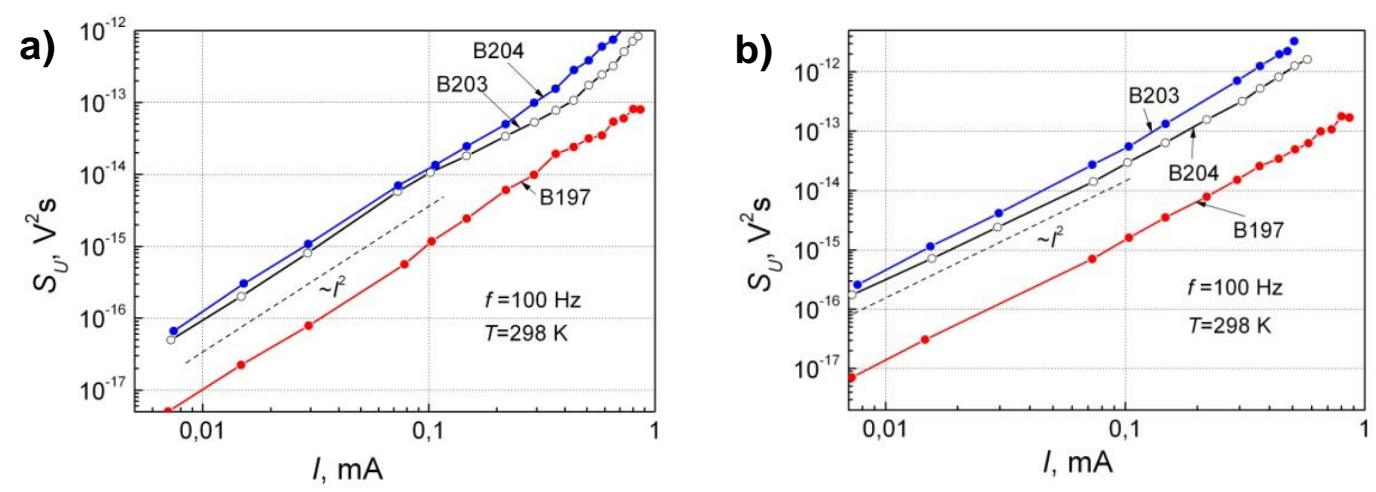

Figure 8. Spectral density voltage fluctuation dependence on bias current for forward (a) and backward current directions (b) at room temperature and frequency $f=100 \mathrm{~Hz}$. 
The $1 / f$ noise level in the backward current direction is slightly higher than that in the forward one, and this correlates with the fact that the differential resistance in the backward current direction is larger than that in the forward direction. The low-frequency noise level at room temperature for the detector B197 is about an order of magnitude lower than that for other samples, because the differential resistance at room temperature for this detector is also about two-times smaller (Figure 6). This result is related to the smaller In/Ga BEP ratio during growth of sample B197 and its small surface roughness (rms). From the point of view of the low-frequency noise level, the optimal BEP In/Ga ratio is 2.04. According to Equation (4), the parameter $K$ describing the localized defect density for this sample is about an order of magnitude smaller than that for other diodes.

The low-frequency noise level dependences on temperature at different frequencies for the investigated detectors are presented in Figure 9. The noise peaks appear at particular temperatures due to the random telegraph signals (RTS) observed, when the Fermi energy level coincides with the energy of the defect capture center. The low-frequency noise is consistent with the model of individual fluctuators (capture centers) affecting the resistance locally over a small area, independent of the full area of the device [32]. The power spectrum of the resistance fluctuations due to the defect $k$ can be written as [32]:

$$
S_{R k}(f)=\frac{4\left\langle\Delta R_{k}^{2}\right\rangle}{\left(\left\langle\tau_{e}\right\rangle+\left\langle\tau_{c}\right\rangle\right)\left[\left(\frac{1}{\tau_{e f f}}\right)^{2}+(2 \pi f)^{2}\right]},
$$

where

$$
\frac{1}{\tau_{e f f}}=\frac{1}{\left\langle\tau_{e}\right\rangle}+\frac{1}{\left\langle\tau_{c}\right\rangle}
$$

$\left\langle\tau_{e}\right\rangle$ is the average time until the electron is emitted from the $k$ defect energy level, and $\left\langle\tau_{c}\right\rangle$ is the average time until the electron is captured by the defect level.

The local resistance fluctuations cause the voltage fluctuations (Figure 9), when the DC current flows through the device, and the spectral density of voltage fluctuations due to all active traps $N_{\text {tr }}$ in the device can be described as

$$
S_{U}=4 I^{2} \sum_{k=1}^{N_{t r}}\left\langle\Delta R_{k}^{2}\right\rangle \frac{\tau_{e f f}}{\left\langle\tau_{e}\right\rangle+\left\langle\tau_{c}\right\rangle} \cdot \frac{\tau_{e f f}}{1+\left(2 \pi \tau_{e f f}\right)^{2}},
$$

where the summation is performed over all traps $\left(k=1,2, \ldots, N_{t r}\right)$ contained in the InGaAs layers and their interfaces. The relative resistance $R$ changes $\Delta R_{k} / R \sim 1 / A$, where $A$ is the InAs surface area, and for a constant trap density $N_{t r} \sim A$. If the total number of traps $N_{t r}$ is sufficiently large to ensure the wide distribution of the time constant, and if $\left\langle\Delta R_{k}^{2}\right\rangle$ value for every $k$ defect is about the same order, then one can obtain the $1 / f$-type noise spectrum.

In the case of dot centers, which have the same energy level, one would expect irregular RTS signals, and the noise spectra with peaks, as it is shown in Figure 9. These noise spectra can be fitted with a few Lorentzian-type spectra (Equation (8)) with a small background of $1 / f$ noise component. The Equation (8) reaches the maximal value when the Fermi level coincides with the defect localization energy in the bandgap. In this case, $\left\langle\tau_{k e}\right\rangle=\left\langle\tau_{k c}\right\rangle$. From these peaks, one can evaluate the effective relaxation times (Equation (7)), and their changes with temperature because every peak fulfils the condition: $2 \pi f_{0 k} \tau_{k \text { eff }}=1$.

In order to highlight the effective relaxation time changes, it is convenient to represent the obtained experimental results at different fixed frequencies, as shown in Figure 9. As it is seen from Figure 9a, the noise peak position for the detector B197 is practically independent of temperature. This happens at a specific temperature when the Fermi energy level is located in a continuum of defect energies, which causes a very wide distribution of relaxation times. In the case of the sample B197 (Figure 9a) at temperatures of $127 \mathrm{~K}, 160 \mathrm{~K}, 213 \mathrm{~K}, 234 \mathrm{~K}$ and $265 \mathrm{~K}$, the relaxation time distribution ranges exceed 
the interval from $15 \mu$ s to $5 \mathrm{~ms}$. As it is seen, other samples, B203 and B204 (Figure 9b,c), express stronger dependences on temperature in comparison to B197.
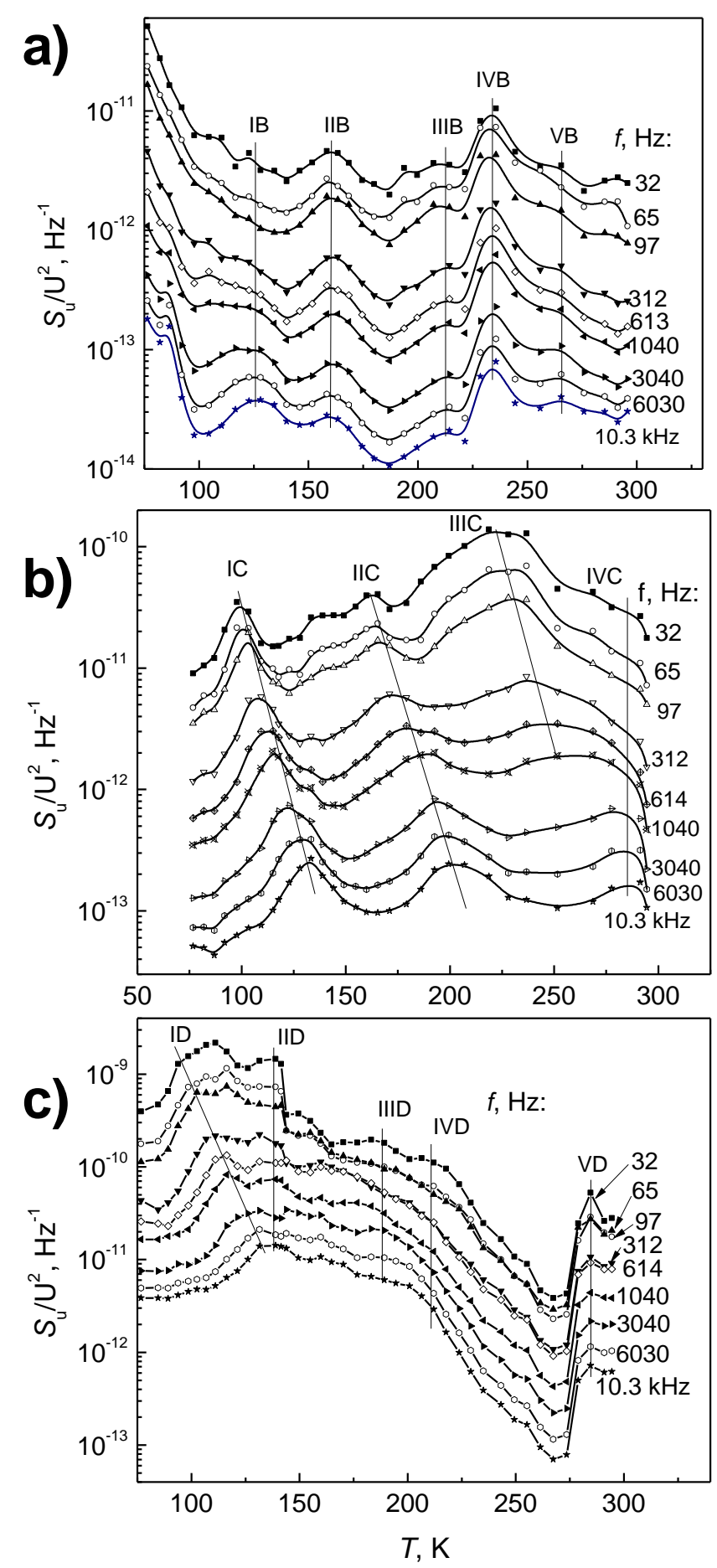

Figure 9. The normalized noise level dependences on temperature at different frequencies (a) for detector B197; (b) for B203; (c) for B204. The lines are included as a guide for the eye and illustrate changes of the noise peak groups.

The evaluated relaxation times for every group of peaks of the investigated detectors are shown in Figure 10. 

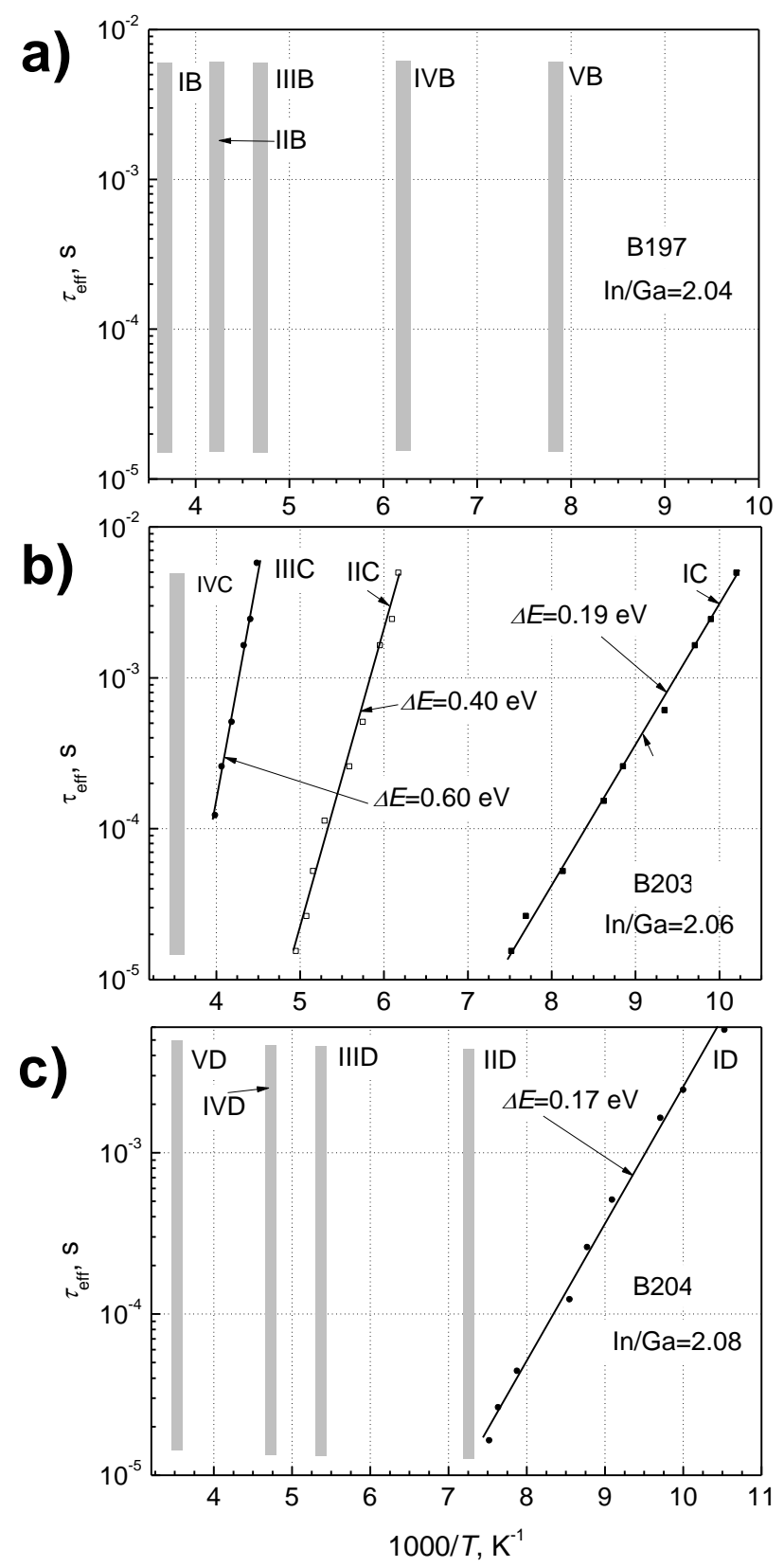

Figure 10. The relaxation time dependences on temperature for the investigated InGaAs bow-tie detectors with different In/Ga ratios: (a) for B197; (b) for B203; (c) for B204. Vertical columns represent the interval of the distribution of relaxation times at definite temperatures, calculated from the Figure 9. The evaluated activation energies are indicated near the relevant curves.

\section{Terahertz Sensitivity Measurement Results and Discussion}

The bow-tie diodes were fabricated using lithography and wet etching technologies following the design of the bow-tie sensors described in [13]. The responsivity measurements of the InGaAs bow-tie detectors have been performed by $30 \mathrm{~mW}$ power radiation at frequency of $0.3 \mathrm{THz}$ and $0.8 \mathrm{~mW}$ at $0.6 \mathrm{THz}$ at modulation frequency of $1 \mathrm{kHz}$. The device position in the $\mathrm{THz}$ beam was set by raster scanning of the incident beam (Figure 11b) at the focal plane. The load resistance was set to $2.4 \mathrm{k} \Omega$ at $0.3 \mathrm{THz}$ and $4.3 \mathrm{k} \Omega$ at $0.6 \mathrm{THz}$, respectively. The DC current was changed from $-0.3 \mathrm{~mA}$ to $0.3 \mathrm{~mA}$, where positive voltage was connected to the metalized taper part of the antenna. The results of the experimental investigation are presented in Figure 11. 

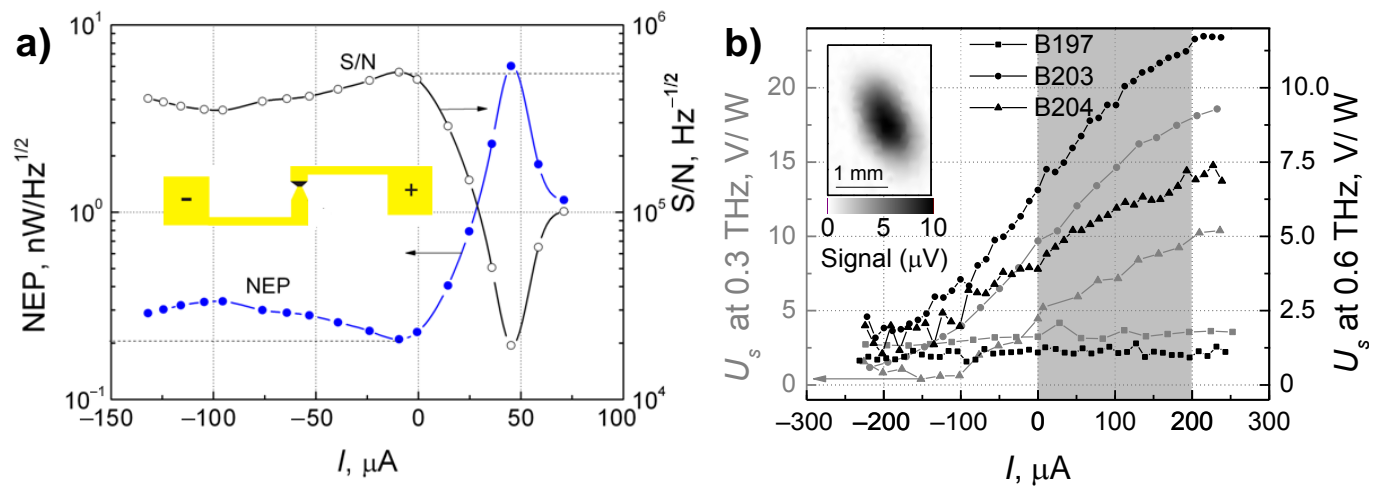

Figure 11. The noise equivalent power (NEP) at $0.6 \mathrm{THz}$ (a) and voltage sensitivity (b) of the InGaAs diode detector with different $\mathrm{In} / \mathrm{Ga}$ ratios at $0.3 \mathrm{THz}$ and $0.6 \mathrm{THz}$ frequency with modulation frequency of $1 \mathrm{kHz}$. Inset in the panel (a) shows the schematic design of the InGaAs bow-tie diode. Inset in the panel $(\mathbf{b})$ indicates the raster scan of the $0.6 \mathrm{THz}$ beam profile at the focal plane obtained with detector B203. Shadowed area in panel (b) indicates optimal working regime of the detector.

The NEP of the B203 sample as a function of current (panel (a) of Figure 11) shows weak dependence at negative bias, and the minimal value of around $200 \mathrm{pW} / \sqrt{ } \mathrm{Hz}$ is reached when the current approaches zero value. With the increase of forward bias the NEP value reaches the maximal value of $6 \mathrm{nW} / \sqrt{ } \mathrm{Hz}$ at $5 \mu \mathrm{A}$. It is worth noting that the minimal NEP value obtained here-around $200 \mathrm{pW} / \sqrt{ } \mathrm{Hz}$ - is much smaller than that reported earlier—4 $\mathrm{nW} / \sqrt{ } \mathrm{Hz}$ [13]—due to the more optimal growth conditions.

Figure $11 \mathrm{~b}$ depicts the sensitivity as a function of current for all types of the studied samples at frequencies of $0.3 \mathrm{THz}$ and $0.6 \mathrm{THz}$. At is seen, sensitivity of InGaAs bow-tie diodes fabricated from the wafers B203 and B204 increases while raising the current and reaches $17.5 \mathrm{~V} / \mathrm{W}$ and $10 \mathrm{~V} / \mathrm{W}$ at $0.3 \mathrm{THz}$ and $12.5 \mathrm{~V} / \mathrm{W}$ and $7 \mathrm{~V} / \mathrm{W}$ at $0.6 \mathrm{THz}$, respectively, at the bias current of $0.2 \mathrm{~mA}$. Higher voltage sensitivity of the detector B203 is caused by the larger asymmetry in the $I-V$ curves and stronger built-in electric fields in comparison to other studied samples. Raster scan of $\mathrm{THz}$ beam profile at $0.6 \mathrm{THz}$ (inset in panel (b) of Figure 11) illustrates the suitability of the diode for $\mathrm{THz}$ imaging aims.

Hence, operation parameters of the InGaAs-based bow-tie diodes can be optimized by varying conditions of the MBE growth. If the In/Ga BEP ratio is kept equal to 2.04, it allows one to reduce the low-frequency noise into the lowest level among the studied structures. The increase of the In/Ga $\mathrm{BEP}$ ratio to 2.06 enables one to increase the internal electric fields in the structure up to $49 \mathrm{kV} / \mathrm{cm}$, making such wafers well suited for fabrication of sensitive-13 V/W and NEP of $200 \mathrm{pW} / \sqrt{ } \mathrm{Hz}$ at $0.6 \mathrm{THz}$-room temperature bow-tie $\mathrm{THz}$ detectors and their further implementation in compact $\mathrm{THz}$ imaging systems [33]. The In/Ga BEP ratio set to 2.08 permits one to achieve the highest crystallinity; however, the internal electric fields-up to $25 \mathrm{kV} / \mathrm{cm}$ - seem to be not strong enough to provide maximal sensitivity values in the investigated diodes.

\section{Conclusions}

Noise characteristics of InGaAs bow-tie diodes are investigated over the temperatures from $77 \mathrm{~K}$ to $300 \mathrm{~K}$. The voltage fluctuation spectral density varies proportionally to $1 / f$ at room temperature, and Lorentzian-type noise spectra appear at lower temperatures. The origin of the fluctuations in the investigated bow-tie diodes is related to the defects caused by charge carrier capture centers involved in generation and recombination processes with characteristic times from a few microseconds to tens of milliseconds. The estimated activation energies of these centers are found to be in the range from $0.15 \mathrm{eV}$ to $0.36 \mathrm{eV}$. It is supposed that they are associated with the presence of the interface defects close to the InAs layer located between the InGaAs layer and InP substrate. The $\mathrm{THz}$ detectors grown with beam equivalent pressure In/Ga ratio equal to 2.04 exhibit the minimal level of the low-frequency noise, while InGaAs layers grown with beam equivalent pressure In/Ga ratio equal to 2.06 are found 
to be well suited for fabrication of room temperature bow-tie $\mathrm{THz}$ detectors enabling sensitivity of $13 \mathrm{~V} / \mathrm{W}$ and $\mathrm{NEP}$ of $200 \mathrm{pW} / \sqrt{ } \mathrm{Hz}$ at $0.6 \mathrm{THz}$ due to strong built-in electric field effects.

Supplementary Materials: The following are available online at http:/ /www.mdpi.com/1424-8220/18/11/3760/s1. Figure S1: The noise measurement circuit: $\mathrm{S}$ is the investigated bow-tie detector; $R_{\mathrm{L}}$ denotes the load resistor; $R_{\text {ref }}$ is the reference resistor; LNA stands for the low-noise amplifier; ADC labels the analog-to-digital converter (National InstrumentsTM PCI 6115 board); PC is the personal computer; Osc. shows the oscilloscope; Cr. indicates the cryostat (DN 7704); and V denotes the voltmeter.

Author Contributions: Conceptualization, G.V., L.M. and R.B.; Methodology, V.P., R.B., J.M., and G.V.; Growth by MBE and structural investigation, R.B.; Photoluminescence investigation, B.C.; Low-frequency noise investigation V.P., S.P. and J.M.; THz investigation, L.M., D.J. and D.S.; Writing-Original Draft Preparation, V.P. and G.V.; Writing-Review \& Editing, V.P., S.P., J.M., L.M., D.S. and G.V.; Visualization, D.J. and L.M.; Supervision, G.V.

Funding: This research was funded by Lietuvos Mokslo Taryba (LAT 04/2016)—project KITKAS.

Acknowledgments: We kindly acknowledge Remigijus Juškènas for possibility to perform structural analysis of grown wafers and Vincas Tamošiūnas for useful discussions.

Conflicts of Interest: The authors declare no conflict of interest.

\section{References}

1. Carmody, C.; Tan, H.H.; Jagadish, C.; Gaarder, A.; Marcinkevičius, S. Ion-implanted InGaAs for ultrafast optoelectronic applications. Appl. Phys. Lett. 2003, 82, 3913-3915. [CrossRef]

2. Dziuba, Z.; Przesławski, T.; Dybko, K.; Górska, M.; Marczewski, J.; Regiński, K. Negative magnetoresistance and impurity band conduction in an $\mathrm{In}_{0.53} \mathrm{Ga}_{0.47} \mathrm{As} / \mathrm{InP}$ heterostructure. J. Appl. Phys. 1999, 85, 6619-6624. [CrossRef]

3. Przesławski, T.; Wolkenberg, A.; Regiński, K.; Kaniewski, J. Sensitive $\operatorname{In}_{0.53} \mathrm{Ga}_{0.47} \mathrm{As} / \mathrm{InP}$ (SI) magnetic field sensors. Phys. Status Solidi 2004, 1, 242-246. [CrossRef]

4. Molis, G.; Krotkus, A.; Vaičaitis, V. Intervalley separation in the conduction band of InGaAs measured by terahertz excitation spectroscopy. Appl. Phys. Lett. 2009, 94, 091104. [CrossRef]

5. Krotkus, A. Semiconductors for terahertz photonics. J. Phys. D Appl. Phys. 2010, 43, 273001. [CrossRef]

6. Mangeney, J.; Merigault, A.; Zerounian, N.; Crozat, P.; Blary, K.; Lampin, J.F. Continuous wave terahertz generation up to $2 \mathrm{THz}$ by photomixing on ion-irradiated InGaAs at $1.55 \mu \mathrm{m}$ wavelengths. Appl. Phys. Lett. 2007, 91, 241102. [CrossRef]

7. Baker, C.; Gregory, I.S.; Evans, M.J.; Tribe, W.R.; Linfield, E.H.; Missous, M. All-optoelectronic terahertz system using low-temperature-grown InGaAs photomixers. Opt. Express 2005, 13, 9639-9644. [CrossRef] [PubMed]

8. Kim, N.; Han, S.-P.; Ko, H.; Leem, Y.A.; Ryu, H.-C.; Lee, C.W.; Lee, D.; Jeon, M.Y.; Noh, S.K.; Park, K.H. Tunable continuous-wave terahertz generation/detection with compact $1.55 \mu \mathrm{m}$ detuned dual-mode laser diode and InGaAs based photomixer. Opt. Express 2011, 19, 15397-15403. [CrossRef] [PubMed]

9. Lusakowski, J.; Knap, W.; Dyakonova, N.; Varani, L.; Mateos, J.; Gonzalez, T.; Roelens, Y.; Bollaert, S.; Cappy, A.; Karpierz, K. Voltage tuneable terahertz emission from a ballistic nanometer InGaAs/InAlAs transistor. J. Appl. Phys. 2005, 97, 064307. [CrossRef]

10. El Fatimy, A.; Teppe, F.; Dyakonova, N.; Knap, W.; Seliuta, D.; Valušis, G.; Shchepetov, A.; Roelens, Y.; Bollaert, S.; Cappy, A.; et al. Resonant and voltage-tunable terahertz detection in InGaAs/ InP nanometer transistors. Appl. Phys. Lett. 2007, 89, 131926. [CrossRef]

11. Seliuta, D.; Kašalynas, I.; Tamošiūnas, V.; Balakauskas, S.; Martūnas, Z.; Ašmontas, S.; Valušis, G.; Lisauskas, A.; Roskos, H.G.; Köhler, K. Silicon lens-coupled bow-tie InGaAs-based broadband terahertz sensor operating at room temperature. Electron. Lett. 2006, 42, 825-827. [CrossRef]

12. Kašalynas, I.; Seliuta, D.; Simniškis, R.; Tamošiūnas, V.; Köhler, K.; Valušis, G. Terahertz imaging with bow-tie InGaAs-based diode with broken symmetry. Electron. Lett. 2009, 45, 833-835. [CrossRef]

13. Minkevičius, L.; Tamošiūnas, V.; Kašalynas, I.; Seliuta, D.; Valušis, G.; Lisauskas, A.; Boppel, S.; Roskos, H.G.; Köhler, K. Terahertz heterodyne imaging with InGaAs-based bow-tie diodes. Appl. Phys. Lett. 2011, 99, 131101. [CrossRef]

14. Kašalynas, I.; Venckevičius, R.; Seliuta, D.; Grigelionis, I.; Valušis, G. InGaAs-based bow-tie diode for spectroscopic terahertz imaging. J. Appl. Phys. 2011, 110, 114505. [CrossRef] 
15. Kašalynas, I.; Venckevičius, R.; Valušis, G. Continuous wave spectroscopic terahertz imaging with InGaAs bow-tie diodes at room temperature. IEEE Sens. J. 2013, 13, 50-54. [CrossRef]

16. Minkevičius, L.; Tamošiūnas, V.; Kojelis, M.; Žąsinas, E.; Bukauskas, V.; Šetkus, A.; Butkutè, R.; Kašalynas, I.; Valušis, G. Influence of Field Effects on the Performance of InGaAs-Based Terahertz Radiation Detectors. J. Infrared Millim. Terahertz Waves 2017, 38, 689-707. [CrossRef]

17. Sužiedèlis, A.; Ašmontas, S.; Gradauskas, J.; Valušis, G.; Roskos, H.G. Giga- and terahertz frequency band detector based on an asymmetrically-necked n-n+-GaAs planar structure. J. Appl. Phys. 2003, 93, 3034-3038. [CrossRef]

18. Seliuta, D.; Širmulis, E.; Tamošiūnas, V.; Balakauskas, S.; Ašmontas, S.; Sužiedèlis, A.; Gradauskas, J.; Valušis, G.; Lisauskas, A.; Roskos, H.G.; et al. Detection of terahertz/sub-terahertz radiation by asymmetrically-shaped 2DEG layers. Electron Lett. 2004, 40, 631-632. [CrossRef]

19. Boppel, S.; Lisauskas, A.; Krozer, V.; Roskos, H.G. Performance and performance variations of sub-1 THz detectors fabricated with $0.15 \mu \mathrm{m}$ CMOS foundry process. Electron. Lett. 2011, 47, 661-662. [CrossRef]

20. Jones, B.K. Electrical noise as a reliability indicator in electronic devices and components. IEE Proc. Circuits Dev. Syst. 2002, 149, 13-22. [CrossRef]

21. Pralgauskaitè, S.; Palenskis, V.; Matukas, J.; Šaulys, B.; Kornijčuk, V.; Verdingovas, V. Analysis of mode-hopping effect in Fabry-Pérot multiple-quantum well laser diodes via low frequency noise investigation. Solid State Electron. 2013, 79, 104-110. [CrossRef]

22. Dobbert, J.; Tran, L.; Hatami, F.; Masselink, W.T.; Kunets, V.T.; Kunets, V.P.; Salamo, G.J. Low frequency noise in InSb/GaAs and InSb/Si channels. Appl. Phys. Lett. 2010, 97, 102101. [CrossRef]

23. Chisum, J.D.; Grossman, E.N.; Popović, Z. A general approach to low noise readout of terahertz imaging arrays. Rev. Sci. Instrum. 2011, 82, 065106. [CrossRef] [PubMed]

24. Minkevičius, L.; Ragauskas, M.; Matukas, J.; Palenskis, V.; Pralgauskaitè, S.; Seliuta, D.; Kašalynas, I.; Valušis, G. InGaAs Bow-tie Diodes for Terahertz Imaging: Low Frequency Noise Characterization. In Proceedings of the SPIE Terahertz Emitters, Receivers, and Applications III, San Diego, CA, USA, 12-13 August 2012; Razeghi, M., Baranov, A.N., Everitt, H.O., Zavada, J.M., Manzur, T., Eds.; Volume 8496, p. 849612. [CrossRef]

25. Shen, H.; Dutta, M. Franz-Keldysh oscillations in modulation spectroscopy. J. Appl. Phys. 1995, 78, 2151-2176. [CrossRef]

26. Čechavičius, B.; Kavaliauskas, J.; Krivaitè, G.; Seliuta, D.; Valušis, G.; Halsall, M.P.; Steer, M.J.; Harrison, P. Photoreflectance and surface photovoltage spectroscopy of beryllium-doped GaAs/AlAs multiple quantum wells. J. Appl. Phys. 2005, 98, 023508. [CrossRef]

27. Mott, N.F.; Davis, E.A. Electronic Processes in Non-Crystalline Materials, 2nd ed.; Oxford University Press: New York, NY, USA, 2012; ISBN 978-0-19-964533-6.

28. Ambegaokar, V.; Halperin, B.I.; Langer, J.S. Hopping Conductivity in Disordered Systems. Phys. Rev. B 1971, 4, 2612-2620. [CrossRef]

29. Palenskis, V.; Maknys, K. Nature of low frequency noise in homogeneous semiconductors. Sci. Rep. 2015, 5, 18305. [CrossRef] [PubMed]

30. Palenskis, V. The charge carrier capture-emission process-The main source of the low-frequency noise in homogeneous semiconductors. Lith. J. Phys. 2016, 56, 200-206. [CrossRef]

31. Palenskis, V.; Glemza, J.; Vysniauskas, J.; Matukas, J. Carrier density and mobility fluctuations due to carrier retrapping process in homogeneous semiconductors. In Proceedings of the 24th International Conference on Noise and Fluctuations (ICNF), Vilnius, Lithuania, 20-23 June 2017.

32. Kirton, M.J.; Uren, M.J. Noise in solid-state microstructures: A new perspective in individual defects, interface states and low-frequency (1/f) noise. Adv. Phys. 1989, 38, 367-468. [CrossRef]

33. Venckevičius, R.; Minkevičius, L.; Reklaitis, A.; Tamošiūnas, V.; Kašalynas, I.; Jokubauskis, D.; Seliuta, D.; Voisiat, B.; Račiukaitis, G.; Valušis, G. Compact solutions for spectroscopic solid-state based terahertz imaging systems. In Proceedings of the SPIE Terahertz Emitters, Receivers, and Applications VIII, San Diego, CA, USA, 6-10 August 2017; Razeghi, M., Baranov, A.N., Pavlidis, D., Zavada, J.M., Eds.; Volume 10383, p. 103830S. [CrossRef]

(C) 2018 by the authors. Licensee MDPI, Basel, Switzerland. This article is an open access article distributed under the terms and conditions of the Creative Commons Attribution (CC BY) license (http:/ / creativecommons.org/licenses/by/4.0/). 